\title{
CIVIL WARS AND INTERNATIONAL TRADE
}

\section{Philippe Martin}

Paris School of Economics (Université

Paris 1 Panthéon Sorbonne)

\section{Thierry Mayer}

Paris School of Economics (Université

Paris 1 Panthéon Sorbonne), CEPII

\section{Mathias Thoenig}

University of Geneva and Paris School

of Economics

\begin{abstract}
This article analyzes empirically the relationship between civil wars and international trade. We first show that trade destruction due to civil wars is very large and persistent and increases with the severity of the conflict. We then identify two effects that trade can have on the risk of civil conflicts: It may act as a deterrent if trade gains are put at risk during civil wars, but it may also act as an insurance if international trade provides a substitute to internal trade during civil wars. We find support for the presence of these two mechanisms and conclude that trade openness may deter the most severe civil wars (those that destroy the largest amount of trade) but may increase the risk of lower-scale conflicts. (JEL: F10, F51, F52, F59)
\end{abstract}

\section{Introduction}

Since the end of the Cold War, democratization and increased integration in the world economy have often been advocated in order to promote prosperity and peace in poor countries. In this article, we focus on the relation between international trade and civil wars, an endemic form of violence in poor countries (see Collier and Rohner 2008 for an analysis of the effect of democracy on the risk of civil wars). We identify two possible mechanisms relating international trade and civil wars: deterrence and insurance. Whereas the first effect is such that trade openness lowers the risk of civil wars, the second one works in the opposite direction.

\footnotetext{
Acknowledgments: We thank Mathieu Couttenier for his help on data for exports of primary products and Daron Acemoglu, Lisa Chauvet, Paul Collier, Torsten Persson, and Dominic Rohner for helpful comments. All errors remain ours. We thank Institut Universitaire de France to which Philippe Martin is also affiliated and the ANR (06-CONF-016-01) for financial assistance. The authors are also affiliated to CEPR.

E-mail addresses: Martin: philippe.martin@univ-paris1.fr; Mayer: Thierry.Mayer@univ-paris1.fr; Thoenig: Mathias.Thoenig@ecopo.unige.ch
} 
Our hypothesis is the following. Because civil wars destroy international trade, some of the economic gains generated by trade are put at risk for all groups (rebels and government) involved so that the opportunity cost of conflict increases with observed trade flows. From this point of view, a larger openness to international trade should act as a deterrent to escalation towards civil conflicts. However, international trade provides a substitute to internal trade during civil wars as it provides alternative sources of income and consumption. From this point of view, it can act as an insurance and can reduce the opportunity cost of civil war. Another way to state this argument is that international trade can weaken economic ties and dependence between groups and regions inside a country as trade with foreign countries can become a substitute to internal trade. This reduced dependence decreases the opportunity cost of conflicts. This line of reasoning resembles the one made in an earlier report (Martin, Mayer, and Thoenig [forthcoming]) showing that multilateral trade openness increases the probability of a bilateral conflict between countries. In that paper, we showed that violence can arise between two parties because of failure to avert escalation of a dispute on how to appropriate a surplus. In the presence of asymmetric information, for example on the military or political strength of the two parties, the escalation is possible and depends on the opportunity cost of a violent conflict for both parties. A higher opportunity cost increases the incentive to make concessions in order to avert escalation. Our hypothesis in the present article is that international trade can affect the opportunity cost of civil conflicts through both deterrence and insurance effects. In order to test for the existence of these two mechanisms, we first check that more intense conflicts destroy more trade. Hence, the deterrence effect should be more important for those conflicts. Also, the insurance effect is weaker for those conflicts. At the extreme, the insurance effect disappears if all international trade is destroyed during civil wars.

The initial motivation for civil war as well as its financial feasibility may also be related to international trade. This argument has been made for commodity exports by Collier and Hoeffler (2007) and Collier, Hoeffler, and Rohner (2007) and discussed critically by Fearon (2005). Higher primary commodity exports can provide opportunities for predation by rebel groups and therefore help finance the rebellion. They can also constitute a motivation for rebel groups to capture the rent. The rent extorted from natural resources is most valuable to the extent that it can be exported. Given that this channel has been extensively studied in the literature we do not focus on it, but we control for the share of primary exports over GDP in all our regressions so as to check that the deterrence and insurance effects of trade openness on the probability of civil war do not follow from this feasibility and motivation effect.

In political science, several recent reports (Barbieri and Reuveny 2005; Bussmann and de Soysa 2005; Bussmann and Schneider 2007) report a negative 
correlation between trade openness and the risk of civil war. These studies do not, however, take into account the issue of reverse causality. A clear problem is that the negative correlation may be due to the fact that civil wars durably destroy trade-something we indeed show and quantify. Hence, a methodological objective of this article is to attempt to solve this reverse causality issue with the use of instruments. Section 2 briefly presents the data used, and Section 3 presents our results on the empirical relation between trade and civil conflicts. Section 4 concludes.

\section{Data}

The data used in this article combine several statistical sources. For civil wars, we mainly use the Correlates of War source, and more precisely the expanded version provided by Kristian Skrede Gleditsch ${ }^{1}$ and detailed in Gleditsch (2004). This data set also allows us to detect the most intense conflicts by providing indication of the number of battle deaths involved. The median of this figure in the data set, when positive, is 30,000 . We define an intense civil war as involving more than 50,000 casualties. Our typical sample includes all countries available in the civil war data set over the 1945-2001 period, where information for right-hand-side variables (in particular trade) is available. Column (4) of Table 1, for instance, has 4,356 observations, of which 4,040 exhibit no civil war, 316 (7.2\%) have a civil war, and 119 have an intense one. For robustness purposes, we also use the expanded version of the Uppsala/PRIO Armed Conflict Dataset, used by Gates and Strand (2004). Regarding intensity, the PRIO data set is not as precise and only reports when the number of battle deaths is higher than 1,000 which we use as our indicator of intensity. The PRIO data set classifies many more events as civil wars. In column (7), the 4,356 observations have $768(17.6 \%)$ civil wars, of which 593 have more than 1,000 battle deaths.

Other data come from standard sources: Trade uses IMF DOTS data, augmented as in Martin, Mayer, and Thoenig (forthcoming). GDP and population data come mostly from World Bank WDI, completed by Barbieri (2002). Primary exports ratios are constructed from the trade dataset of Robert Feenstra. ${ }^{2}$ Democracy comes from the Polity IV project. Ethnic fractionalization comes from Alesina's Web site. All gravity-related variables come from the CEPII database.

1. <http://privatewww.essex.ac.uk/ ksg/expwar.html>.

2. As our definition of primary products, we take what has been standard in the literature: food, beverages, crude materials, fuels, and nonferrous metals. We add SITC 667, which lists all precious stones, pearls, and so on. 


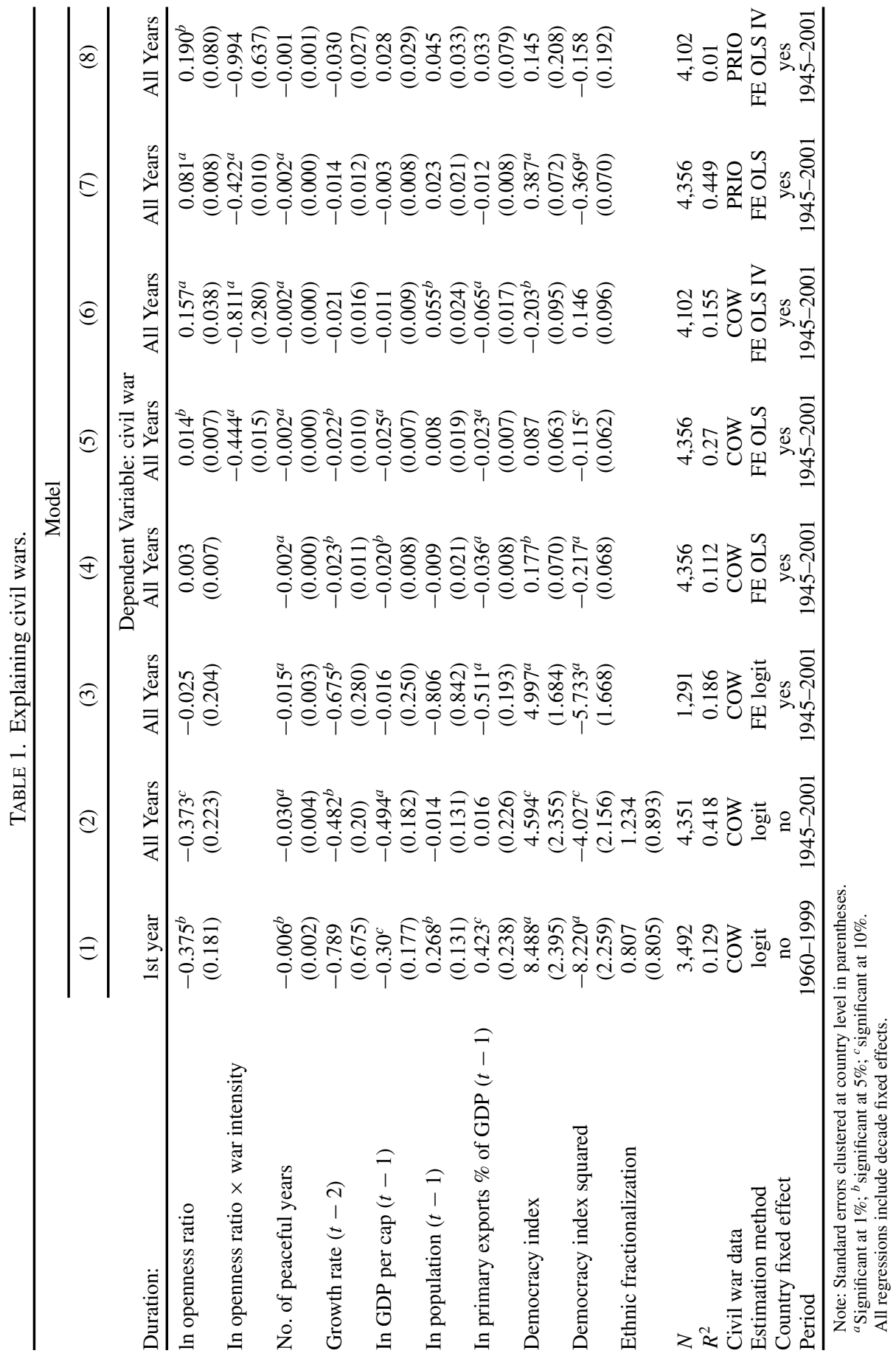




\section{Results}

\subsection{The Effect of Civil Wars on International Trade}

The first step in our analysis is to quantify the size and persistence of the destruction of international trade by civil wars. We do this in a very standard fashion by estimating gravity equations which measure increases in trade costs (related to infrastructure, rule of law, information, trust, etc.) due to a civil war. Note that this effect comes in addition to the impact civil wars have on trade through their negative impact on income. ${ }^{3}$

Left in the equation to be estimated is an exporter GDP term, and a vector of the traditional proxies for trade costs, all expressed relative to the United States. The list of proxies for trade costs include bilateral distance, contiguity, colonial linkages, a dummy indicating whether one country has a communist regime, common membership in a regional trade area, and a variable counting the number of GATT/WTO member in the country pair. To this list we add lags and leads of dummies indicating the occurrence of a civil war in the importing or the exporting country. Coefficients on those dummies measure the trade (exports and imports) impact of such conflicts and the persistence of this impact over time.

Detailed results are available upon request, and results on usual variables are very similar to usual findings, with, for instance, a near unitary coefficient on incomes, a coefficient near -1 for distance, and a positive impact of regional agreements. For the sake of clarity we choose a graphical representation of our results of interest. Figure 1 shows, using this regression, the fall in trade after a civil war relative to "natural" (i.e., gravity-predicted) trade with $10 \%$ confidence intervals in bands (the coefficients are smoothed using a two-year window around the year of interest). The gray squares represent the impact of the most intense civil wars (the ones with reported casualties over 50,000 deaths), and the black triangles represent the impact of less severe crises.

The effect of a severe civil war is both very large on contemporaneous trade and very persistent: We observe a fall in trade around $25 \%$ from its natural level in the first year of the conflict. This controls for the level of GDP

\footnotetext{
3. As emphasized by Anderson and Van Wincoop (2004), all theoretical foundations of the gravity equation predict bilateral trade flows to be a function of trade partners' incomes and bilateral trade impediments, but also of what they call "multilateral resistance terms," a complex function of incomes and trade costs of all trade partners in a given year. Omitting those terms biases the estimates of changes in trade costs of the type we want to measure. As in Martin, Mayer, and Thoenig (forthcoming) and Romalis (2007), we use a convenient feature of CES demand functions that makes relative imports from a given exporter independent of the characteristics of third countries. Multilateral resistance terms are eliminated in the bilateral trade equation by choosing the imports from the United States as a benchmark of comparison for all imports of each importing country. It also eliminates the GDP term of the importing country.
} 


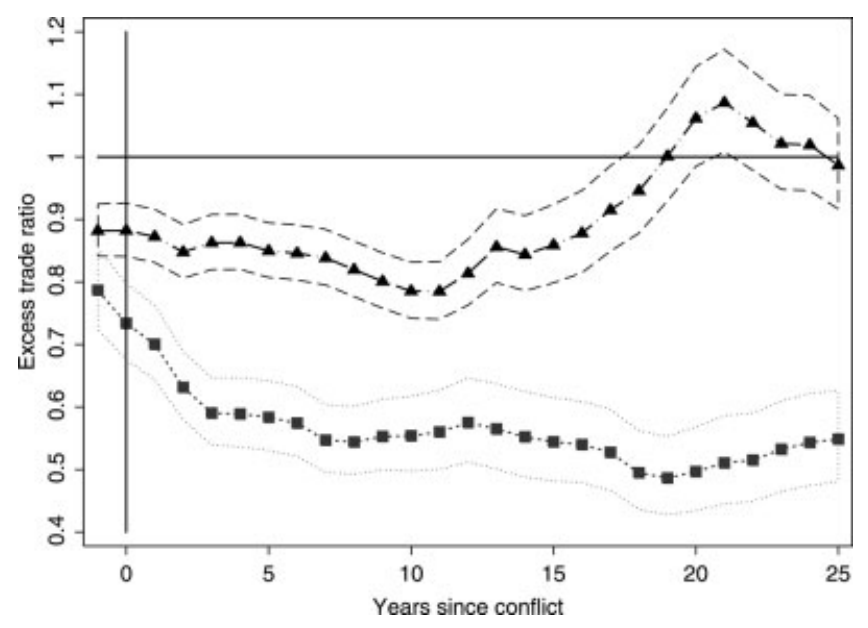

FIGURE 1. The impact of civil wars on trade.

(which typically also falls during civil wars) so that the total fall in trade is actually larger. The destruction of trade becomes larger with time and is extremely persistent as it is still present at around 40\% 25 years after the conflict's onset. This is in contrast with interstate wars where the effect is large when looking at bilateral trade between the two belligerents but is not as persistent and is very small for multilateral trade of two belligerents (Blomberg and Hess 2006; Martin, Mayer, and Thoenig [forthcoming]). For less-severe conflicts, the effect is smaller but still present and persistent. It, however, disappears after around 20 years. Interestingly, the fall in trade anticipates the onset of the civil war. Many explanations can be given to this finding but it points clearly to an endogeneity issue in previous empirical studies that have found a negative impact of trade on the risk of civil wars (Barbieri and Reuveny 2005; Bussmann and de Soysa 2005).

\subsection{The Impact of Trade Openness on the Risk of Civil War}

We now analyze the impact of trade openness on the probability of civil war and attempt to identify the two effects we discussed in the Introduction: deterrence and insurance. Because the deterrence effect depends positively on the expected destruction of trade, we can infer from the previous section results that deterrence is stronger in the case of the most-severe civil wars. Hence our empirical strategy consists in disentangling the deterrence and insurance effects by comparing the differential effect of trade openness on low- versus high-intensity civil wars. We estimate the probability of a civil war in country $i$ at time $t$ with the following 
regression:

$$
\operatorname{Pr}\left(\text { war }_{i t}\right)=\gamma_{0}+\gamma_{1} \text { controls }_{i t}+\left(\gamma_{2}+\gamma_{3} \text { intensity }_{i t}\right) \times \ln \left(\sum_{j \neq i}^{R} \frac{m_{i j t}}{E_{i t}}\right),
$$

where $\sum_{j \neq i}^{R} m_{i j t} / E_{i t}$ represents multilateral import flows as ratios of income and intensity $_{i t}$ is a dummy variable equal to one for high-intensity civil wars. The presence of an insurance mechanism in trade is consistent with a positive impact of trade on the probability of civil war so we expect $\gamma_{2}>0$. The presence of a deterrence effect is identified by a negative effect of trade openness on the wars that are most destructive in terms of trade, that is, the high-intensity wars. Hence, we expect: $\gamma_{3}<0$.

Table 1 shows both the pooled results (first two columns) and the fixed effects results (last six columns). The interaction term $\gamma_{3}$ featuring in equation (1) is tested in regressions (5) to (8).

In regressions (1) to (4), we replicate some of the results obtained in the existing literature. In regression (1), we use a logit specification predicting the onset of civil wars for the 1960-1999 period. We introduce a number of standard controls: The number of peaceful years (since the last civil war); the growth rate of the country at time $t-2$, the $\log$ of the GDP per capita at $t-1$, the $\log$ of population at time $t-1$, the log of the share of primary exports in GDP, the index of democracy and its squared value, and finally an index of ethnic fractionalization. In all regressions, decade fixed effects are added. ${ }^{4}$ The first two columns therefore pool a very large number of countries over roughly half a century each. The error term is thus likely to exhibit correlation patterns for a given country, and we cluster the (robust) standard errors at the country level to take this into account. The controls have the usual sign (see Fearon 2005 for a comparable specification) but their significance is lower than in the existing literature because of clustered standard errors. In this first regression, the correlation between the probability of civil war and trade openness is negative and very significant as in the existing literature. However, this coefficient is difficult to interpret due to the reverse causality issue discussed in the previous section. The second regression has similar results for a logit equation that has all years of civil wars (and not only the onset of it). From regression (3), we systematically introduce country fixed effects in our specifications. ${ }^{5}$ In the logit version of column (3), the identification of the country fixed effects is made only within countries that experienced a civil war at some point in our time frame: This means that all countries that never experienced a civil war are dropped from the sample. We thus choose to

4. The introduction of five-year fixed effects does not change the results qualitatively. Year fixed effects leave signs unchanged but reduce the significance of some coefficients.

5. In this case, ethnic fractionalization which is not time varying is dropped. 
switch to OLS regressions with fixed effects as this less stringent specification allows to retain all observations. As shown in column (4), the OLS results are very similar to the logit ones: In both cases trade openness is not significant and, for the other covariates, the direction and the significance of the effects are similar.

Starting with regression (5), equation 1 is tested and we attempt to identify the two effects of trade openness by introducing an interaction term between trade openness and the intensity of the civil war. The results are consistent with our hypothesis that trade openness affects the probability of a civil war through both an insurance and a deterrence effect. For low-intensity civil wars, trade openness increases the probability of a civil war. However, for high-intensity ones, trade openness reduces the risk of civil war as the coefficient on the interacted term is larger (in absolute value) than the non-interacted one. In regression (5), the hypothesis is tested with a fixed effects OLS specification. Both coefficients are significant and of the right sign. We have checked that using only observations for the onset of civil wars gives similar results. A possible alternative explanation of the positive sign on trade openness is that it helps finance or motivate the rebellion. Remember, however, that we control for the share of primary exports in GDP. Hence, this suggests that the positive sign on trade openness for low intensity conflicts does not come from the fact that higher exports of primary commodities facilitate the financing of rebellion.

In regression (6), we attempt to solve the endogeneity issue by using instrumental variables. Given that we have two endogenous variables (trade and trade interacted with war intensity), we need to use at least two instrumental variables. We choose the log of remoteness of the country and a dummy for membership of the country in GATT/WTO. Both variables are lagged two years so as to give them time to affect trade openness. The remoteness variable is routinely used in the international trade literature as one of the determinants of trade flows (see Baier and Bergstrand 2004) and as an instrument for trade openness. Intuitively, remoteness measures each importer's set of alternative trade partners. A country with low remoteness has many nearby and large alternative sources of goods and increases its multilateral imports and is therefore more open to trade. Following the literature, our definition of the remoteness variable is

$$
\text { remoteness }_{i t}=-\ln \left(\sum_{j \neq i}^{R} \mathrm{GDP}_{j t} / d_{i j}\right),
$$

where $d_{i j}$ is bilateral distance between $i$ and $j$. The main interest of the remoteness variable is that it varies in the time dimension for a given country $i$-this is a key feature given that our regressions include country fixed effects. First-stage regressions (unreported due to space constraints but available upon request) show that our two instruments have the expected effects on trade openness (negative 
for remoteness and positive for GATT/WTO membership) for both the COW and PRIO data sets. The $F$-test statistics lie around 80 , indicating very powerful instruments. Unsurprisingly, the instruments are weaker when explaining trade openness interacted with civil war intensity. In fact, only GATT/WTO membership seems a significant covariate in this case, strongly for the COW civil wars, weaker in the case of PRIO.

Regression (6) is our preferred specification (instrumental variables, country fixed effects, decade fixed effects). The two coefficients of interest, $\gamma_{2}$ and $\gamma_{3}$ in equation (1), have the expected sign and are significant at the $1 \%$ level. In regressions (7) and (8), we check whether our results also hold when we use the PRIO data set. Broadly, the results are confirmed. However, in the specification with instrumental variables (regression 8), the interaction term, although it has the right sign, is not significant. This is very likely to come from the fact that in this data set, none of our instruments is very strong for the interaction term.

\section{Conclusion}

We find support for the hypothesis that trade openness of a country affects its risk of civil war. Trade openness increases the risk of low intensity conflicts but decreases the risk of high-intensity conflicts. We interpret this result as evidence that international trade affects the risk of civil war through two mechanisms that play in opposite direction: insurance and deterrence.

\section{References}

Anderson, James E., and Eric van Wincoop (2004). "Trade Costs." Journal of Economic Literature, XLII, 691-751.

Baier, Scott L., and Jeffrey H. Bergstrand (2004). "Economic Determinants of Free Trade Agreements." Journal of International Economics, 64, 29-63.

Barbieri, Katherine (2002). The Liberal Illusion: Does Trade Promote Peace? University of Michigan Press.

Barbieri, Katherine, and Rafael Reuveny (2005). "Economic Globalization and Civil War." Journal of Politics, 67(4), 1228-1247.

Blomberg, Brock, and Gregory D. Hess (2006). "How Much Does Violence Tax Trade?” Review of Economics and Statistics, 88(4), 599-612.

Bussmann, Margit, and Indra de Soysa (2005). "How Taxing Is Trade? Globalization, State Capacity, \& Civil War." Working paper, University of Konstanz.

Bussmann, Margit, and Gerald Schneider (2007). "When Globalization Discontent Turns Violent: Foreign Economic Liberalization and Internal War." International Studies Quarterly, 51(1), 79-97.

Collier, Paul, and Anke Hoeffler (2007). "Civil War.” In Handbook of Defense Economics, vol. 2, edited by Todd Sandler and Keith Hartley. North Holland.

Collier, Paul, Anke Hoeffler, and Dominic Rohner (2007). "Beyond Greed and Grievance: Feasibility and Civil War." Discussion paper, Oxford University. 
Collier, Paul, and Dominic Rohner (2008). "Democracy, Development and Conflict." Journal of the European Economic Association, Papers and Proceedings, 6(2-3), 531-540.

Fearon, James (2005). "Primary Commodity Exports and Civil War." Journal of Conflict Resolution, 49, 483-507.

Gates, Scott, and Håvard Strand (2004). "Modeling the Duration of Civil Wars: Measurement and Estimation Issues." PRIO working paper, available from http://www.prio.no/.

Gleditsch, Kristian (2004). "A Revised List of Wars between and within Independent States, 1816-2002.” International Interactions, 30, 231-262.

Martin, Philippe, Thierry Mayer, and Mathias Thoenig (forthcoming). "Make Trade Not War?" Review of Economic Studies.

Romalis, John (2007). "NAFTA's and CUSFTA's Impact on International Trade." Review of Economics and Statistics, 89(3), 416-435. 